\title{
Article
}

Mycosphere

\author{
Doi 10.5943/mycosphere/9/5/4
}

\section{Additions to Pestalotiopsis in Taiwan}

\section{Ariyawansa $\mathrm{HA}^{1}$ and Hyde $\mathrm{KD}^{2}$}

\author{
${ }^{1}$ Department of Plant Pathology and Microbiology, College of Bio-Resources and Agriculture, National Taiwan \\ University, Taiwan \\ ${ }^{2}$ Center of Excellence in Fungal Research, Mae Fah Luang University, Chiang Rai 57100, Thailand
}

Ariyawansa HA, Hyde KD 2018 - Additions to Pestalotiopsis in Taiwan. Mycosphere 9(5), 999-1013, Doi 10.5943/mycosphere/9/5/4

\begin{abstract}
As part of fungal exploration of Taiwan, we found several pestalotioid taxa from Taipei Botanical Gardens, Zhongzheng District. Based on single- and multi-locus phylogenies using internal transcribed spacer, $\beta$-tubulin and partial translation elongation factor $1-\alpha$ gene regions, along with morphological features, these species fit into two novel taxa of Pestalotiopsis sensu stricto and are proposed herein as Pestalotiopsis formosana and P. neolitseae. Pestalotiopsis formosana and P. neolitseae were isolated from dead grass and living leaves of Neolitsea villosa respectively. These two novel species are morphologically comparable with Pestalotiopsis sensu stricto in having concolourous median cells, but differ from the phylogenetically related species in the size of the conidia, the number of apical appendages, the length of basal appendages, plus ecology and distribution. The results of pathogenicity testing revealed that Pestalotiopsis neolitseae is capable of causing leaf spots on Neolitsea villosa and to the best of our knowledge, this is the first record of Pestalotiopsis species associated with leaf spots of Neolitsea villosa in Taiwan.
\end{abstract}

Key words -2 new taxa - New record - New species - Pestalotioid species - Phylogeny phytopathogenic fungi

\section{Introduction}

The genus Pestalotiopsis was introduced by Steyaert (1949) to accommodate pestalotioid taxa with 5-celled conidia and is presently placed in Sporocadaceae of Amphisphaeriales (Wijayawardene et al. 2017, 2018). With the advent of molecular data, extensive improvements have been incorporated over the past decade in unravelling the phylogenetic resolution within Pestalotiopsis and its allied genera (Maharachchikumbura et al. 2014). Maharachchikumbura et al. (2014) introduced two new genera namely Neopestalotiopsis and Pseudopestalotiopsis to accommodate pestalotiopsis-like species based on morphology, coupled with molecular data. Furthermore, Maharachchikumbura et al. (2014) concluded that these three genera can be identified based on the conidiogenous cells and colour of their median conidial cells, thus the pestalotiopsislike taxa having concolourous median cells were retained in Pestalotiopsis sensu stricto (Maharachchikumbura et al. 2014). Taxa having dark coloured concolourous median cells were categorised in Pseudopestalotiopsis while pestalotioid taxa with versicolourous median cells were placed under Neopestalotiopsis (Maharachchikumbura et al. 2014). Currently, the genus 
Pestalotiopsis comprises 52 phylogenetically verified species, which have been reported from various hosts and habitats (Liu et al. 2017, Maharachchikumbura et al. 2014).

We have been studying pestalotioid taxa from various hosts and habitats in Taiwan to provide the stable molecular based systematic to this chemically diverse fungal group (Ariyawansa et al. 2018, Tsai et al. 2018). During our ongoing investigation, several fungal isolates, which are morphologically comparable to Pestalotiopsis sensu stricto (Maharachchikumbura et al. 2014) were collected from Taipei Botanical Gardens, Zhongzheng District in Taiwan. The aim of this paper is to investigate the taxonomic position of the isolated pestalotioid taxa based on morphology and molecular phylogenetic analyses of internal transcribed spacer (ITS), $\beta$-tubulin (tub2) and partial translation elongation factor $1-\alpha$ gene (tefl).

\section{Materials \& Methods}

\section{Sample collection and fungal isolation}

Thirty naturally infected Neolitsea villosa (Blume) Merr. leaves and 30 dead grass samples were collected from the Taipei Botanical Gardens, Zhongzheng District, Taipei City, Taiwan, during 2017-2018. The samples were brought to the laboratory in Ziplock plastic bags. The specimens were processed and examined following the method described in Ariyawansa et al. (2014, 2016a, b). Fresh materials were observed under a Motic SMZ 168 dissecting microscope to locate and isolate fruiting bodies. Hand sections of the fruiting structures were mounted in water for microscopic studies and photomicrography. Isolations were made from single conidia, following an altered method of Ariyawansa et al. (2018). Morphological descriptions were prepared for isolates cultured on $2 \%$ potato dextrose agar (PDA; Difco). Conidiomatal growth was observed on WA with double-autoclaved pine needles located onto the agar surface (PNA). Cultures were incubated at room temperature $\left(25^{\circ} \mathrm{C}\right)$ for 7 days. Microscopic slide preparations were carried out in distilled water, and as a minimum 30 measurements per structure were noted and observed with an Olympus BX51 microscope using differential interference contrast (DIC) illumination. Taxonomic descriptions are deposited in Facesoffungi (Jayasiri et al. 2015) and nomenclature details in MycoBank. New taxa are decided based on recommendations defined by Jeewon \& Hyde (2016).

Voucher specimens are deposited in the herbarium of Department of Plant Pathology and Microbiology, National Taiwan University (NTUH). Living cultures are deposited at the Department of Plant Pathology and Microbiology, National Taiwan University Culture Collection (NTUCC).

\section{DNA extraction, PCR amplification and sequencing}

Single conidial isolates were grown on PDA for 28 days at $25{ }^{\circ} \mathrm{C}$ in the dark. Genomic DNA was extracted from the growing mycelium following the method described in Ariyawansa et al. (2018). The PCR amplification process was carried out as described by Tsai et al. (2018). Primer sets used for these genes were as follows: ITS5/ITS4 (White et al. 1990), BT2A/BT2B (Glass \& Donaldson 1995, O’Donnell \& Cigelnik 1997), and EF1-728F/EF2 (Rehner 2001, Liu et al. 2017) respectively. The PCR reactions for amplification of ITS (Schoch et al. 2012), were accomplished under regular conditions (White et al. 1990, Stielow et al. 2010). Amplification of tub2 and tef1 followed the protocol of Maharachchikumbura et al. (2014). The PCR products were visualized on $1.5 \%$ agarose electrophoresis gels stained with SYBR safe DNA gel stain. Purification and sequencing of PCR products was carried at Genomics, New Taipei, Taiwan. Consensus sequences from sequences generated from forward and reverse primers were obtained via DNASTAR Lasergene SeqMan Pro v.8.1.3. Sequences are placed at NCBI GenBank under the accession numbers provided in Supplementary Table 1.

\section{Sequence alignment and phylogenetic analysis}

Multiple sequence alignments were produced with MAFFT v. 6.864b (http://mafft.cbrc.jp/alignment/server/index.html). The alignments were tested visually and 
improved manually where needed. Regions covering many leading or trailing gaps were discarded from the alignments prior to tree building. All sequences obtained from GenBank and used by Chen et al. (2018), Liu et al. (2017), Maharachchikumbura et al. (2014), Nozawa et al. (2017) are listed in Supplementary Table 1. To decide closely allied taxa, single gene phylogenies were inferred for ITS, tub2 and tefl and lastly subjected to a multigene combined analysis.

MrModeltest v. 2.3 (Nylander 2004) under the Akaike Information Criterion (AIC) was implemented in PAUP v. $4.0 \mathrm{~b} 10$ used to determined evolutionary models for phylogenetic analyses. Comparison of the alignment properties and nucleotide substitution models for each gene locus are provided in Table 1.

A maximum likelihood analysis was done at the CIPRES webportal (Miller et al. 2010) using RAxML-HPC2 on XSEDE (v 8.2.8) with default parameters and bootstrapping with 1000 replicates (Stamatakis 2014). The resulting replicates were marked on to the best scoring tree acquired previously. Maximum Likelihood bootstrap values (ML) equal or greater than $70 \%$ are given below or above each node (Fig. 1).

Markov Chain Monte Carlo sampling (MCMC) implemented in MrBayes v. 3.0b4 (Huelsenbeck \& Ronquist 2001) was used to calculate Posterior probabilities (BP) (Rannala \& Yang 1996, Zhaxybayeva \& Gogarten 2002). Six simultaneous Markov chains were initially run for $1 \times 10^{10}$ generations and every $100^{\text {th }}$ generation a tree was sampled (critical value for the topological convergence diagnostic set to 0.01 , options of "stoprule $=$ yes" and "stopval $=0.01$ "). MCMC heated chain was set with a "temperature" value of 0.15 . The distribution of log-likelihood scores was observed to decide stationary phase for each search and to check if further runs were required to reach convergence, using the program Tracer 1.5 (Rambaut \& Drummond 2007). All sampled topologies below the asymptote (20\%) were removed as part of a burn-in process, the remaining trees were used for computing posterior probabilities in the majority rule consensus tree. BP equal or greater than 0.95 are given below or above each node (Fig. 1).

In order to decide the species boundaries in Pestalotiopsis sensu stricto, we applied the principles of Genealogical Concordance Phylogenetic Species Recognition (GCPSR) (Taylor et al. 2000, Dettman et al. 2003). Dettman et al. (2003) underlined that species should be acknowledged if they satisfy one of two criteria: genealogical concordance or genealogical non-discordance. Clades were genealogically concordant if they were existing in at least some of the gene trees and genealogically non-discordant if they were strongly supported (ML $\geq 70 \% ; \mathrm{BP} \geq 0.95$ ) in a single loci and not contradicted at or above this level of support in any other single gene tree. This standard prohibited poorly supported non-monophyly at one locus from undermining well-supported monophyly at another locus. Phylogenetic trees and data files were viewed in MEGA v. 5 (Tamura et al. 2011), TreeView v. 1.6.6 (Page 2001) and FigTree v. 1.4 (Rambaut \& Drummond 2008).

\section{Pathogenicity test}

The pathogenicity of NTUCC $17-011$ and NTUCC $17-012$ isolates were tested on healthy leaves of Neolitsea villosa obtained from the initial collection sites at Taipei Botanical Garden, Taipei city, Taiwan. The upper and lower sides of leaves were sterilized with $70 \%$ ethanol. For each isolate, 15 leaves on Neolitsea villosa leaves were artificially inoculated. An agar plug $(1 \mathrm{~cm}$ diam) with mycelium was cut from the border of five days-old culture grown on PDA medium (25 $\left.{ }^{\circ} \mathrm{C}\right)$. The leaves were separated into three groups, each with five leaves. The first collection of leaves was wounded by pin-pricking and inoculated by agar plugs $(1 \mathrm{~cm}$ diam $)$ with fungal mycelium. Agar plugs with fungal mycelium were located on the surface of a second group comprising unwounded leaves. The leaves of control was not pin-pricked and was inoculated with PDA agar plugs without fungal mycelium. The inoculated test leaves were kept in sterile, moist plastic boxes for 14 days. Observations on the growth of disease symptoms were noted on a daily basis. In order to prove pathogenicity, the inoculated fungi were re-isolated from leaves showing lesions, and the identity of the re-isolated fungi was confirmed by sequencing the ITS, tub2 and tefl loci as described above. 


\section{Results}

\section{Phylogeny}

The topologies of the developed trees for each gene locus were compared manually, to ensure that the general tree topology of the single gene alignments, were comparable to each other and to that of the tree received from the concatenated alignment. The ML analyses showed similar tree topologies and were similar to those obtained in the Bayesian analyses. The results of the molecular phylogenetic analyses are supplied below (Fig. 1).

After exclusion of poorly aligned sites from each locus, the final concatenated data matrix comprised 1888 characters (ITS 559, tub2 781 and tef1 548) from 97 taxa.

The Bayesian analysis resulted in 50000 trees after 50000000 generations after the topological convergence. The first 10000 trees, representing the burn-in phase of the analyses were discarded, while the remaining trees were used for calculating posterior probabilities in the majority rule consensus tree.

A best scoring RAxML tree resulted with the value of Likelihood: -11258.033741 . Phylogenetic trees obtained from ML and Bayesian analysis yielded trees with similar overall topology at the species level in arrangement with earlier studies based on ML and Bayesian analysis (Chen et al. 2018, Maharachchikumbura et al. 2014).

In both ML and Bayesian analyses, clade containing the two strains of Pestalotiopsis NTUCC 17-009 and NTUCC 17-010 form a distinct clade with high statistical support and neighbouring to clade representing Pestalotiopsis parva (CBS 278.35 and CBS 265.37) in both single locus and concatenated datasets analysis. Therefore, the new lineage is introduced here as the new species Pestalotiopsis formosana. Besides, in both single- and multi-gene phylogeny, the two strains of Pestalotiopsis NTUCC 17-011 and NTUCC 17-012 form a separate lineage with high statistical support and basal to Pestalotiopsis jinchanghensis (LC6636 and LC8190) clade in both ML and Bayesian analyses. Hence, the novel taxon Pestalotiopsis neolitseae is proposed to place taxa in the genus Pestalotiopsis.

Table 1 Evaluation of alignment properties of genes and nucleotide substitution models used in the phylogenetic analysis.

\begin{tabular}{llll}
\hline Genes /loci & tef & ITS & $t u b$ \\
\hline Alignment strategy (MAFFT v6) & FFT-NS- & FFT-NS- & FFT-NS- \\
& I+manual & I+manual & I+manual \\
$\begin{array}{l}\text { Nucleotide substitution models for } \\
\begin{array}{l}\text { Bayesian analysis (determined by } \\
\text { MrModeltest) }\end{array}\end{array}$ & GTR+G & GTR+G & GTR+G \\
\hline
\end{tabular}

\section{Taxonomy}

Pestalotiopsis formosana Ariyawansa \& K.D. Hyde, sp. nov.

MycoBank number: MB827597; Facesoffungi number: FoF04937

Etymology - formosana an alternative name used for Taiwan, where this taxon was collected.

Saprobic on grass. Sexual morph: undetermined. Asexual morph: Conidiomata on PDA pycnidial, globose or lenticular, solitary or aggregate, immersed or semi-immersed, exuding black slimy conidial mass on the surface of mycelia. Conidiophores reduce to conidiogenous cells, when present, branched or unbranched, septate, hyaline. Conidiogenous cell discrete, cylindrical to subcylindrical, lageniform, hyaline, tapering to a thin neck, smooth, (5-)9-15(-19) $\times(2-) 2-3(-4)$ $\mu \mathrm{m}, \overline{\mathrm{x}} \pm \mathrm{SD}=11 \pm 3.5 \times 2 \pm 0.4 \mu \mathrm{m}$, proliferating $1-4$ times percurrently, collarette present. Conidia fusoid, straight to slightly curved, 4-septate, $(15-) 18-22(-26) \times(5-) 6-7 \mu \mathrm{m}, \overline{\mathrm{x}} \pm \mathrm{SD}=20$ $\pm 2.1 \times 6 \pm 0.5 \mu \mathrm{m}$; basal cell obconic, cylindrical, with or without a truncate base, hyaline, 


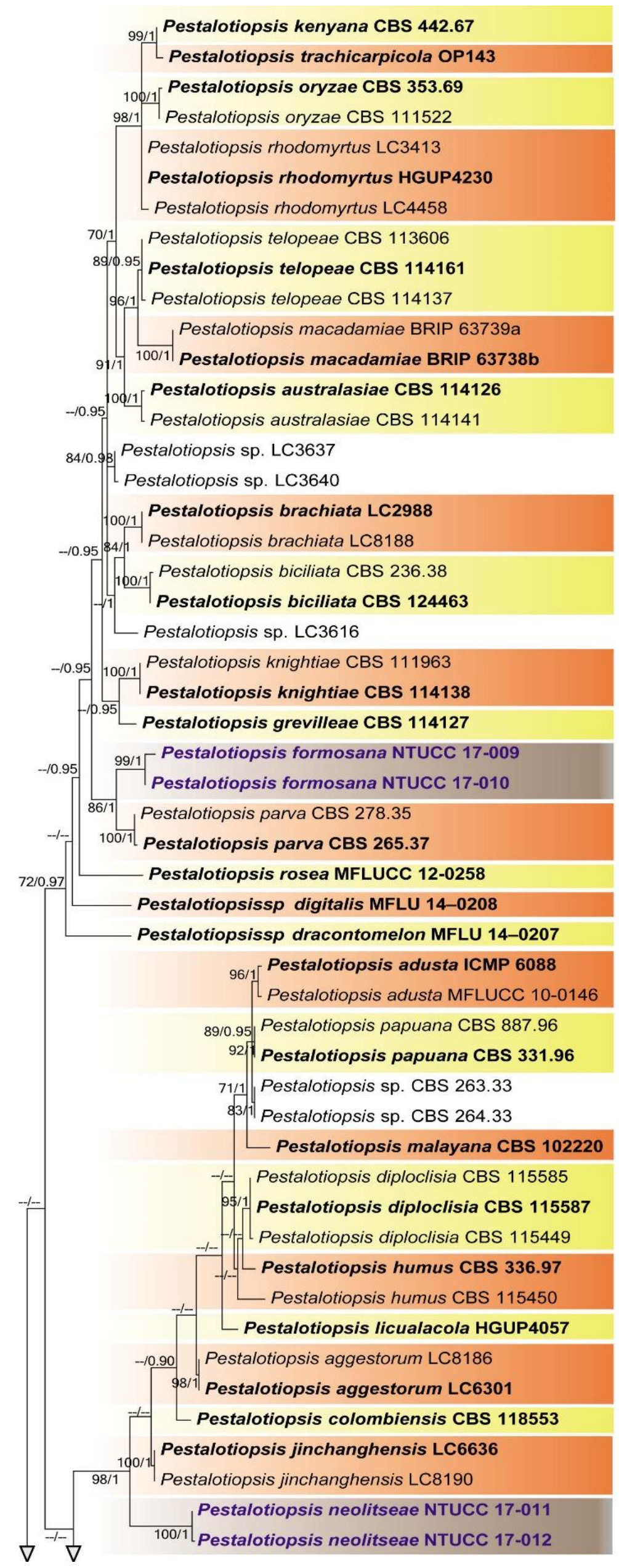




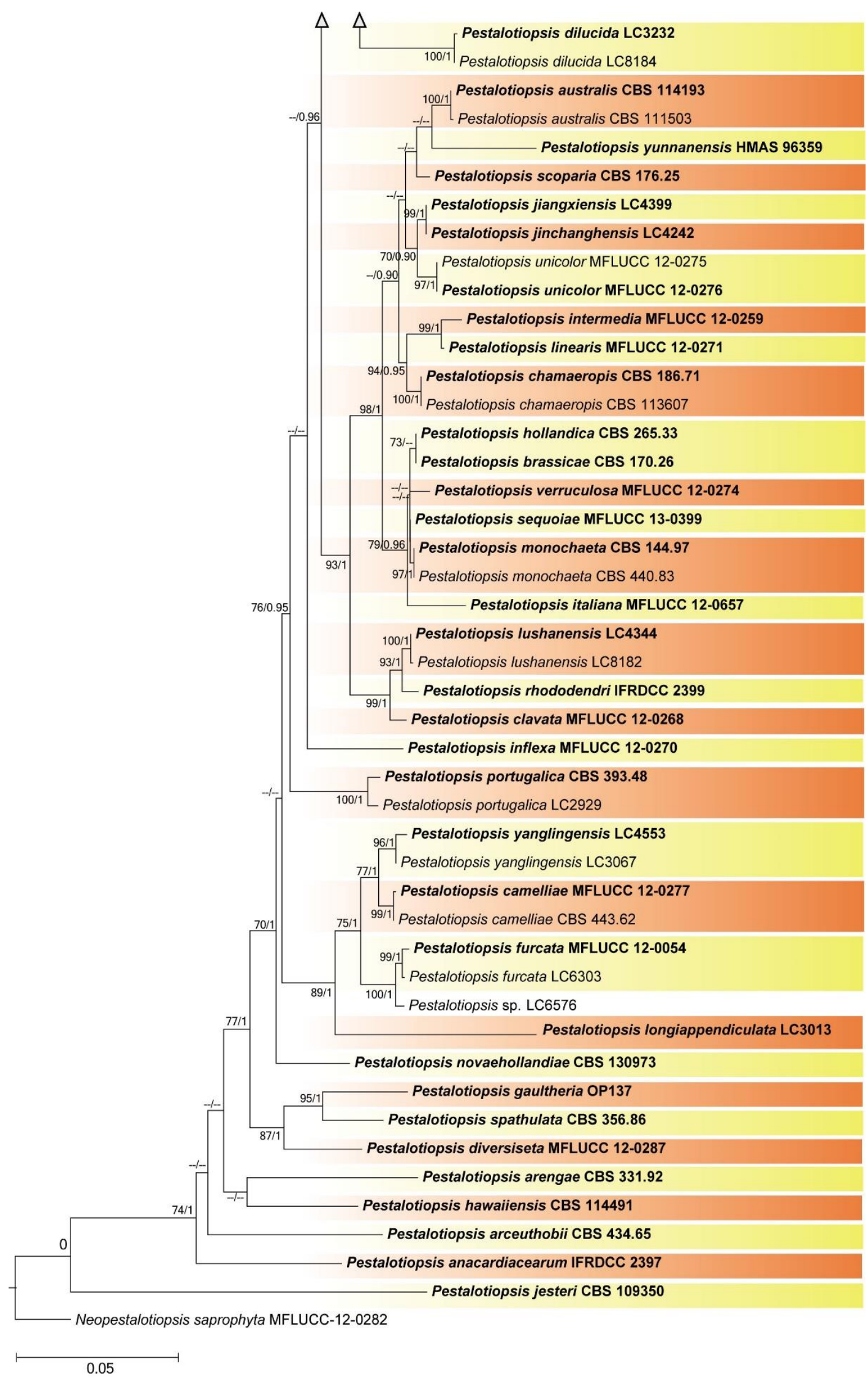

Figure 1 - RAxML tree obtained from the concatenated DNA sequence data of ITS, tub and tefl genes. The novel isolates are shown in blue. Bayesian posterior probabilities (PP) $\geq 0.95$ and ML bootstrap values (BS) $\geq 70 \%$ are given at the nodes. The scale bar shows the number of estimated substitutions per site. Neopestalotiopsis saprophyta (MFLUCC-12-0282) was used as outgroup for rooting the tree. Taxa representing ex-type cultures are in bold. 
smooth - and thin-walled, (3-)4-5(-6) $\mu \mathrm{m}$ long, $\overline{\mathrm{x}} \pm \mathrm{SD}=4 \pm 0.7 \mu \mathrm{m}$; three median cells doliiform, concolourous, pale brown, somewhat verruculose, (10-)11-14(-16) $\mu \mathrm{m}$ long, $\overline{\mathrm{x}} \pm \mathrm{SD}=13 \pm 1.3 \mu \mathrm{m}$ (the second cell from base (3-)4-5(-6) $\mu \mathrm{m}$ long, $\overline{\mathrm{x}} \pm \mathrm{SD}=4 \pm 0.6 \mu \mathrm{m}$; third cell 3-4(-5) $\mu \mathrm{m}$ long, $\overline{\mathrm{x}} \pm \mathrm{SD}=4 \pm 0.5 \mu \mathrm{m}$; fourth cell (3-)4-5 $\mu \mathrm{m}$ long, $\overline{\mathrm{x}} \pm \mathrm{SD}=4 \pm 0.4 \mu \mathrm{m}$ ), wall of the third and fourth cell from the base thicker than that of the second cell, septa darker than the rest of the cells; apical cell cylindrical to subcylindrical, conic, hyaline, smooth- and thin-walled, (2-)3-4 $\mu \mathrm{m}$ long, $\overline{\mathrm{x}} \pm \mathrm{SD}=3 \pm 0.6 \mu \mathrm{m}$; with 2-3 tubular apical appendages (mostly 2), arising from the apical crest, filiform, unbranched, (8-)11-16(-20) $\mu \mathrm{m}$ long, $\overline{\mathrm{x}} \pm \mathrm{SD}=14 \pm 3.0 \mu \mathrm{m}$; basal appendage single, unbranched, centric or excentric, (2-)3-5(-6) $\mu \mathrm{m}$ long, $\overline{\mathrm{x}} \pm \mathrm{SD}=4 \pm 1.0 \mu \mathrm{m}$.

Colony characteristics - Colony on PDA reaching $60 \mathrm{~mm}$ diam after $6 \mathrm{~d}$ at $25{ }^{\circ} \mathrm{C}$, circular, effuse with floccose texture, margin crenate and filamentous, colour white, with aerial mycelia on the surface, with immersed to semi-immersed conidiomata, producing black, glistening spore mass; reverse pale honey-coloured, slightly concentric, with black conidiomata.

Materials examined - TAIWAN, Taipei Botanical Garden, Zhongzheng district, Taipei city, on dead grass (Poaceae) 9 August 2017, I Tsai, BG11.1 (NTUH 17-009; holotype) -ex-holotype living culture (NTUCC 17-009). ibid. (NTUH 17-010; paratype) -ex-paratype living culture (NTUCC 17-010).

Notes - Pestalotiopsis formosana is a unique taxon based on both morphology and phylogeny (Figs 1, 2). Pestalotiopsis formosana differs from its phylogenetically closely related species $P$. parva by the number of apical appendages (mostly two versus mostly three), relatively longer apical appendages (11-16 $\mu \mathrm{m}$ versus 6.5-12 $\mu \mathrm{m}$ ), and host (Poaceae versus Ericaceae or Fabaceae).

Pestalotiopsis neolitseae Ariyawansa \& K.D. Hyde, sp. nov.,

MycoBank number: MB827598; Facesoffungi number: FoF04938

Etymology - The specific epithet neolitseae is based on the host genus Neolitsea.

Pathogenic causing spots on leaves of Neolitsea villosa. Leaf spots circular to irregular, grey with brown margins when mature, or covering up to half of the leaf; dotted with acervuli. Sexual morph: undetermined. Asexual morph: Conidiomata on PDA pycnidial, globose or lenticular, solitary or aggregate, immersed or semi-immersed, exuding black slimy conidial mass on the surface of mycelia. Conidiophores often reduce to conidiogenous cells, when present, branched or unbranched. Conidiogenous cell discrete or integrated, cylindrical to subcylindrical, hyaline, smooth, often tapering to a neck on the septum of developing conidia, $(6-) 7-11(-13) \times(2-) 2-4(-5)$ $\mu \mathrm{m}, \overline{\mathrm{x}} \pm \mathrm{SD}=9 \pm 2.2 \times 3 \pm 0.9 \mu \mathrm{m}$. Conidia ellipsoid, fusoid, straight to slightly curved, 4-septate, $(15-) 18-21(-25) \times(4-) 5-6 \mu \mathrm{m}, \overline{\mathrm{x}} \pm \mathrm{SD}=20 \pm 1.9 \times 6 \pm 0.4 \mu \mathrm{m}$; basal cell obconic, hyaline, smooth- and thin-walled, (3-)3-5(-6) $\mu \mathrm{m}$ long, $\overline{\mathrm{x}} \pm \mathrm{SD}=4 \pm 0.7 \mu \mathrm{m}$; three median cells doliiform, concolourous, pale brown, somewhat verruculose, (10-)11-14(-14) $\mu \mathrm{m}$ long, $\overline{\mathrm{x}} \pm \mathrm{SD}=12 \pm 1.2 \mu \mathrm{m}$ (the second cell from base 3-4(-5) $\mu \mathrm{m}$ long, $\overline{\mathrm{x}} \pm \mathrm{SD}=4 \pm 0.4 \mu \mathrm{m}$; third cell 3-4(-5) $\mu \mathrm{m}$ long, $\overline{\mathrm{x}} \pm$ $\mathrm{SD}=4 \pm 0.4 \mu \mathrm{m}$; fourth cell $4-5(-6) \mu \mathrm{m}$ long, $\overline{\mathrm{x}} \pm \mathrm{SD}=4 \pm 0.4 \mu \mathrm{m})$, wall of the third and fourth cell from the base thicker than that of the second cell, septa darker than the rest of the cells; apical cell cylindrical to subcylindrical, conic to bell-shaped, hyaline, smooth- and thin-walled, (2-)3-4(6) $\mu \mathrm{m}$ long, $\overline{\mathrm{x}} \pm \mathrm{SD}=3 \pm 0.5 \mu \mathrm{m}$; with 1-3 tubular apical appendages (mostly 2), arising from the apical crest, filiform, unbranched or branched, (7-)10-15(-17) $\mu \mathrm{m}$ long, $\overline{\mathrm{x}} \pm \mathrm{SD}=13 \pm 2.5 \mu \mathrm{m}$; basal appendage single, unbranched, straight to curved, centric or excentric, $2-5(-6) \mu \mathrm{m}$ long, $\overline{\mathrm{x}} \pm$ $\mathrm{SD}=4 \pm 0.9 \mu \mathrm{m}$.

Colony characteristics - Colony on PDA reaching $75 \mathrm{~mm}$ diam after $6 \mathrm{~d}$ at $25^{\circ} \mathrm{C}$, circular, effuse with floccose texture, margin crenated and filamentous, colour white, with aerial mycelia on the surface, with immersed to semi-immersed conidiomata, producing black, glistening spore mass; reverse colour whitish pink, centre pale brown, margin pale honey-coloured, with black conidiomata. 
Material examined - TAIWAN, Taipei Botanical Garden, Zhongzheng district, Taipei city, on leaf of Neolitsea villosa (Lauraceae) 9 August 2017, H. A. Ariyawansa, BG2.2 (NTUH 17-011; holotype) - ex-holotype living culture (NTUCC 17-011). ibid. (NTUH 17-012; paratype) - exparatype living culture (NTUCC 17-012).

Notes - Pestalotiopsis neolitseae is typical of Pestalotiopsis in having concolourous median cells and proposed here as a distinctive taxon based phylogeny together with morphology (Figs 1 , 3). Pestalotiopsis neolitseae differs from $P$. jinchanghensis in having smaller conidia $(18-21 \times 5-6$ $\mu \mathrm{m}$ versus $22-32 \times 5.5-8.5 \mu \mathrm{m})$, shorter apical appendages $(10-15 \mu \mathrm{m}$ versus $15-33.5 \mu \mathrm{m})$ and shorter basal appendages $(2-5 \mu \mathrm{m}$ versus 5.5-15.5 $\mu \mathrm{m})$. Furthermore, Pestalotiopsis neolitseae differs from $P$. jinchanghensis by host (Neolitsea versus Camellia), and the geographical location (Taiwan versus mainland China).
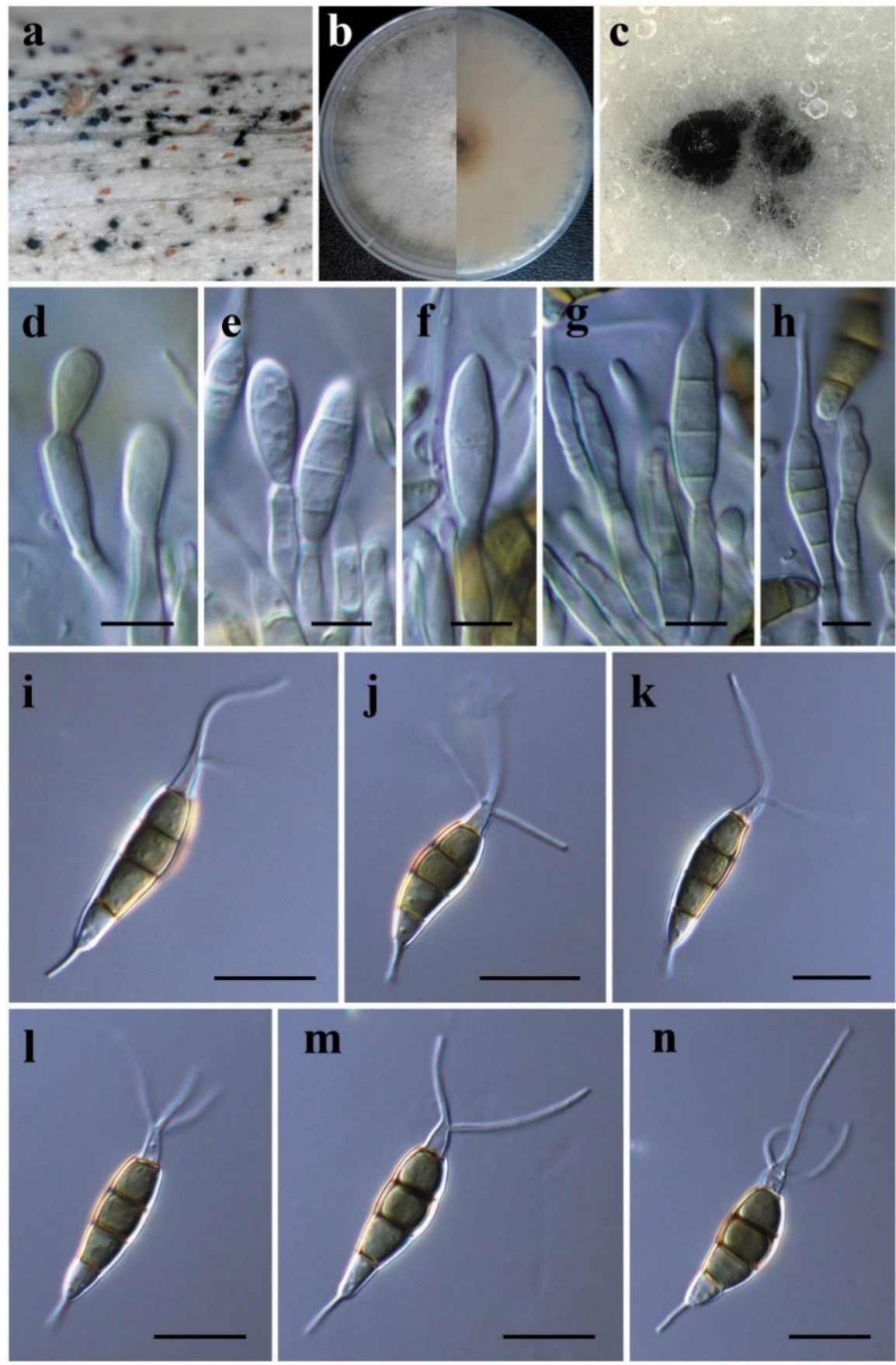

Figure 2 - Pestalotiopsis formosana (holotype). a Immersed conidiomata on host. b Surface and lower sight of colonies on PDA. c Conidioma on PDA. $d-h$ Conidiogenous cells. $\mathrm{i}-\mathrm{n}$ Conidia. Scale bars: d-h $5 \mu \mathrm{m}, \mathrm{i}-\mathrm{n} 10 \mu \mathrm{m}$. 

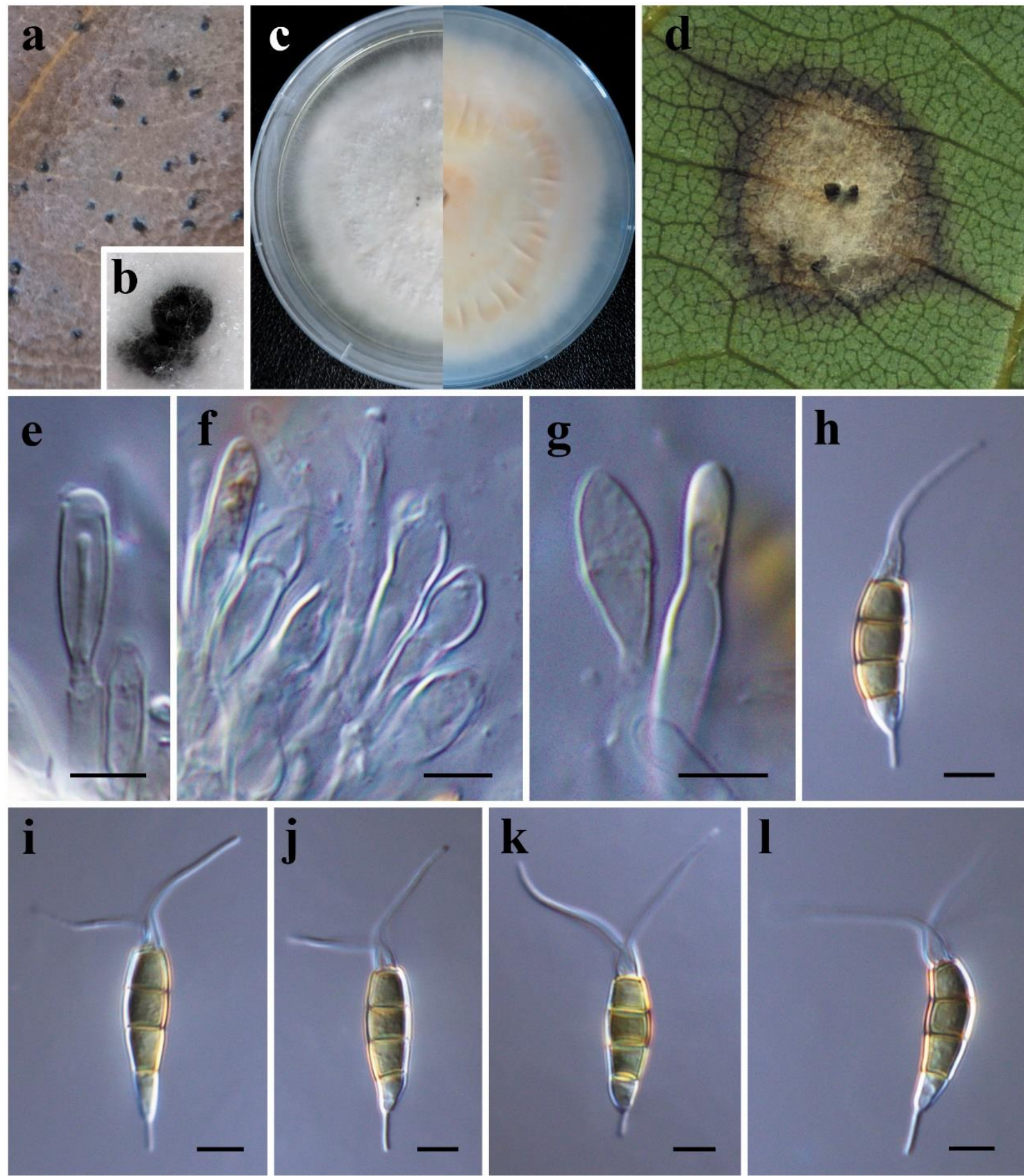

Figure 3 -Pestalotiopsis neolitseae (holotype). a, d Neolitsea villosa leaves with characteristic leaf spots. b Conidioma on PDA. c Surface and lower view of colonies on PDA. e- $\mathrm{h}$ Conidiogenous cells. i-1 Conidia. Scale bars: $\mathrm{d}-\mathrm{k} 5 \mu \mathrm{m}$.

\section{Pathogenicity test}

Results of pathogenicity test revealed that, with wound inoculation, Pestalotiopsis neolitseae was pathogenic on Neolitsea villosa leaves (Fig. 3a, d) and the symptoms induced were similar to those, which occur under natural conditions in the field. The wounded Neolitsea villosa leaves initially developed small, circular, ash-coloured spots, which later changed into brown spots. After 18 days of incubation, the spots prolonged to $5 \mathrm{~mm}$ diam. The spots further enlarged and became sunken causing soft decay of the leaf tissues, covered by white mycelia (Fig. 3d). In contrast, symptoms were not observed on non-wounded leaves, signifying that wounding may be essential for symptom development. The experiment was done using three replicates and repeated three times. The fungus was re-isolated from lesions of the diseased leaves with $100 \%$ frequency, and its morphological features and gene sequences were equal to the original ones, which definite that Pestalotiopsis neolitseae is the causal agents for Neolitsea villosa leaf spot disease. 


\section{Discussion}

Data acquired by traditional morphological recognition of conidial characters are inadequate when identifying species as well as the genus limits in pestalotioid taxa (Ariyawansa et al. 2018, Tsai et al. 2018, Liu et al. 2017, Nozawa et al. 2017, Maharachchikumbura et al. 2013, 2014). Although the morphological recognition of Pestalotiopsis sensu stricto, Pseudopestalotiopsis and Neopestalotiopsis rely on the conidiogenous cells and colour of their median conidial cells, some of the Pestalotiopsis-like species have shown overlapping morphologies of conidiogenous cells and median cell colour (Liu et al. 2017, Nozawa et al. 2017). Therefore, molecular-based polyphasic approaches are essential to recognise the species as well as the generic boundaries of pestalotioid taxa (Ariyawansa et al. 2018, Tsai et al. 2018, Liu et al. 2017, Maharachchikumbura et al. 2014, 2016a, b, Nozawa et al. 2017).

The present survey illustrates two novel species of Pestalotiopsis sensu stricto considering both morphology and phylogeny. The phylogenetic construction of the DNA sequences of single and combined ITS, tub2 and tef1 genes provide robust confirmation that Pestalotiopsis formosana and P. neolitseae fit in Pestalotiopsis sensu stricto and they form separate linages showing the new taxa are separated from other species of the genus with high bootstrap support (Fig. 1). Moreover, we outlined the characters of Pestalotiopsis taxa, which are phylogenetically related to Pestalotiopsis formosana and P. neolitseae in Supplementary Table 2. In addition, our study expands knowledge on the diversity of pestalotioid species in Taiwan and to best of our understanding, this is the first record of Pestalotiopsis species from Neolitsea villosa in Taiwan.

\section{Acknowledgements}

This study was partially funded by the Ministry of Science and Technology, Taiwan (MOST project ID: 106-2621-B-002-005-MY2). We appreciate the support given by Dr. Wei-Fan SU, the director of the Taipei Botanical Gardens, Professors Ting-Hsuan Hung, Ruey-Fen Liou, ChanPin Lin, Wei-Chiang Shen, Associate Professor Ying-Lien Chen and Ms. Ichen Tsai. We are grateful to A.D. Ariyawansa, D.M.K. Ariyawansa, Ruwini Ariyawansa, Amila Gunasekara and Oshen Chemika for their valuable suggestions.

\section{References}

Ariyawansa HA, Hawksworth DL, Hyde KD, Jones EBG et al. 2014 - Epitypification and neotypification: guidelines with appropriate and inappropriate examples. Fungal Diversity 69, 57-91

Ariyawansa HA, Hyde KD, Liu JK, Wu SP, Liu ZY. 2016a - Additions to Karst Fungi 1: Botryosphaeria minutispermatia sp. nov., from Guizhou Province, China. Phytotaxa 275, 3544

Ariyawansa HA, Hyde KD, Thambugala KM, Maharachchikumbura SSN et al. 2016b - Additions to Karst Fungi 2: Alpestrisphaeria jonesii from Guizhou Province, China. Phytotaxa 277, $255-265$.

Ariyawansa HA, Tsai I, Jones EGB. 2018 - A new cryptic species of Pseudopestalotiopsis from Taiwan. Phytotaxa 357(2), 133-140.

Chen Y, Zeng L, Shu N, Jiang M et al. 2018 - Pestalotiopsis-like species causing gray blight disease on Camellia sinensis in China. Plant Disease 102(1), 98-106

Dettman JR, Jacobson DJ, Turner E, Pringle A, Taylor JW. 2003 - Reproductive isolation and phylogenetic divergence in Neurospora: comparing methods of species recognition in a model eukaryote. Evolution 57, 2721-2741.

Glass NL, Donaldson GC. 1995 - Development of primer sets designed for use with the PCR to amplify conserved genes from filamentous ascomycetes. Applied and Environmental Microbiology 61, 1323-1330.

Huelsenbeck JP, Ronquist F, Hall B. 2003 - MrBayes: a program for the Bayesian inference of phylogeny. Version $3.0 \mathrm{~b} 4$. 
Jayasiri SC, Hyde KD, Ariyawansa HA, Bhat DJ et al. 2015 - The faces of fungi database: fungal names linked with morphology, phylogeny and human impacts. Fungal Diversity 74, 3-18.

Jeewon R, Hyde KD. 2016 - Establishing species boundaries and new taxa among fungi: recommendations to resolve taxonomic ambiguities. Mycosphere 7(11), 1669-1677.

Liu F, Hou L, Raza M, Cai L. 2017 - Pestalotiopsis and allied genera from Camellia, with description of 11 new species from China. Scientific Reports 7(1), 866.

Maharachchikumbura SSN, Guo LD, Chukeatirote E, Hyde KD. 2013 - Improving the backbone tree for the genus Pestalotiopsis; addition of $P$. steyaertii and P. magna sp. nov. Mycological Progress 13, 617-624.

Maharachchikumbura SSN, Guo LD, Liu ZY, Hyde KD. 2016b - Pseudopestalotiopsis ignota and Ps. camelliae spp. nov. associated with grey blight disease of tea in China. Mycological Progress 15, 22.

Maharachchikumbura SSN, Hyde KD, Groenewald JZ, Xu J, Crous P. 2014 - Pestalotiopsis revisited. Studies in Mycology 79, 121-186

Maharachchikumbura SSN, Hyde KD, Jones EBG, McKenzie EHC et al. 2016a - Families of Sordariomycetes. Fungal Diversity 79, 1-317.

Miller MA, Pfeiffer W, Schwartz T. 2010 - Creating the CIPRES Science Gateway for inference of large phylogenetic trees. In Gateway Computing Environments Workshop (GCE), 2010 (pp. 1-8). Ieee.

Nozawa S, Yamaguchi K, Van Hop D, Phay N et al. 2017 - Identification of two new species and a sexual morph from the genus Pseudopestalotiopsis. Mycoscience 58(5), 328-337.

Nylander J. 2004 - MrModeltest v2. Program distributed by the author, Evolutionary Biology Centre, Uppsala University, Uppsala, Sweden.

O’Donnell K, Cigelnik E. 1997 - Two divergent intragenomic rDNA ITS2 types within a monophyletic lineage of the fungus Fusarium are nonorthologous. Molecular Phylogenetics and Evolution 7, 103-116.

Page RD. 2001 - TreeView Glasgow University, Glasgow, UK

Rambaut A, Drummond AJ. 2007 - Tracer v1, 4. Available from: http://beast. bio. ed. ac. uk/Tracer (accessed 10 December 2017).

Rambaut A, Drummond AJ. 2008 - FigTree: Tree figure drawing tool, version 1.2. 2.

Rannala B, Yang Z. 1996 - Probability distribution of molecular evolutionary trees: a new method of phylogenetic inference. Journal of Molecular Evolution 43, 304-311.

Rehner S. 2001 - Primers for elongation factor 1- $\alpha$ (EF1- $\alpha)$.

Schoch CL, Seifert KA, Huhndorf S, Robert V et al. 2012 - Nuclear ribosomal internal transcribed spacer (ITS) region as a universal DNA barcode marker for Fungi. Proceedings of the National Academy of Sciences 109, 6241-6246.

Stamatakis A. 2014 - RAxML version 8: a tool for phylogenetic analysis and post-analysis of large phylogenies. Bioinformatics 30, 1312-1313.

Steyaert RL. 1949 - Contributions al'etude monographique de Pestalotia de Not. et Monochaetia Sacc. (Truncatella gen. nov. et Pestalotiopsis gen. nov.). Bulletin Jardin Botanique Etat Bruxelles 19, 285-354.

Stielow B, Bubner B, Hensel G, Munzenberger B et al. 2010 - The neglected hypogeous fungus Hydnotrya bailii Soehner (1959) is a widespread sister taxon of Hydnotrya tulasnei (Berk.) Berk. and Broome (1846). Mycological Progress 9, 195-203.

Tamura K, Peterson D, Peterson N, Stecher G et al. 2011 - MEGA5: molecular evolutionary genetics analysis using maximum likelihood, evolutionary distance, and maximum parsimony methods. Molecular Biology and Evolution 28, 2731-2739.

Taylor JW, Jacobson DJ, Kroken S, Kasuga T et al. 2000 - Phylogenetic species recognition and species concepts in fungi. Fungal Genetics and Biology 31, 21-32.

Tsai I, Maharachchikumbura SSN, Hyde KD, Ariyawansa HA. 2018 - Molecular phylogeny, morphology and pathogenicity of Pseudopestalotiopsis species of Ixora in Taiwan. Mycological Progress 17, 941-952. 
White TJ, Bruns TD, Lee S, Taylor J. 1990 - Amplification and direct sequencing of fungal ribosomal RNA genes for phylogenetics. PCR protocols: a guide to methods and applications $18,315-322$.

Wijayawardene NN, Hyde KD, Rajeshkumar KC, Hawksworth DL et al. 2017 - Notes for genera: Ascomycota. Fungal Diversity 86, 1-594.

Wijayawardene NN, Hyde KD, Lumbsch HT, Liu JK et al. 2018 - Outline of Ascomycota - 2017. Fungal Diversity 88, 167-263.

Zhaxybayeva O, Gogarten JP. 2002 - Bootstrap, Bayesian probability and maximum likelihood mapping: exploring new tools for comparative genome analyses. BMC genomics 3, 4.

Supplementary Table 1 Details of the isolates used in the phylogenetic tree. Newly generated sequences are in red.

\begin{tabular}{|c|c|c|c|c|}
\hline Taxon & Strain ID & ITS & tub & tef \\
\hline Pestalotiopsis kenyana & CBS 442.67 & KM199302 & KM199395 & KM199502 \\
\hline Pestalotiopsis trachicarpicola & OP143 & JQ845947 & JQ845945 & JQ845946 \\
\hline Pestalotiopsis oryzae & CBS 353.69 & KM199299 & KM199398 & KM199496 \\
\hline Pestalotiopsis oryzae & CBS 111522 & KM199294 & KM199394 & KM199493 \\
\hline Pestalotiopsis rhodomyrtus & LC3413 & KX894981 & KX895313 & KX895198 \\
\hline Pestalotiopsis rhodomyrtus & HGUP4230 & KF412648 & KF412642 & KF412645 \\
\hline Pestalotiopsis rhodomyrtus & LC4458 & KX895010 & KX895342 & KX895228 \\
\hline Pestalotiopsis telopeae & CBS 113606 & KM199295 & KM199402 & KM199498 \\
\hline Pestalotiopsis telopeae & CBS 114161 & KM199296 & KM199403 & KM199500 \\
\hline Pestalotiopsis telopeae & CBS 114137 & KM199301 & KM199469 & KM199559 \\
\hline Pestalotiopsis macadamiae & BRIP 63739a & KX186589 & KX186681 & KX186622 \\
\hline Pestalotiopsis macadamiae & BRIP 63738b & KX186588 & KX186680 & KX186621 \\
\hline Pestalotiopsis australasiae & CBS 114126 & KM199297 & KM199409 & KM199499 \\
\hline Pestalotiopsis australasiae & CBS 114141 & KM199298 & KM199410 & KM199501 \\
\hline Pestalotiopsis sp. & LC3637 & KX894993 & KX895324 & KX895210 \\
\hline Pestalotiopsis sp. & LC3640 & KX894995 & KX895326 & KX895212 \\
\hline Pestalotiopsis brachiata & LC2988 & KX894933 & KX895265 & KX895150 \\
\hline Pestalotiopsis brachiata & LC8188 & KY464142 & KY464162 & KY464152 \\
\hline Pestalotiopsis biciliata & CBS 236.38 & KM199309 & KM199401 & KM199506 \\
\hline Pestalotiopsis biciliata & CBS 124463 & KM199308 & KM199399 & KM199505 \\
\hline Pestalotiopsis sp. & LC3616 & KX894990 & KX895321 & KX895207 \\
\hline Pestalotiopsis knightiae & CBS 111963 & KM199311 & KM199406 & KM199495 \\
\hline Pestalotiopsis knightiae & CBS 114138 & KM199310 & KM199408 & KM199497 \\
\hline Pestalotiopsis grevilleae & CBS 114127 & KM199300 & KM199407 & KM199504 \\
\hline Pestalotiopsis formosana & NTUCC 17-009 & MH809381 & MH809385 & MH809389 \\
\hline Pestalotiopsis formosana & NTUCC 17-010 & MH809382 & MH809386 & MH809390 \\
\hline Pestalotiopsis parva & CBS 278.35 & KM199313 & KM199405 & KM199509 \\
\hline Pestalotiopsis parva & CBS 265.37 & KM199312 & KM199404 & KM199508 \\
\hline Pestalotiopsis rosea & $\begin{array}{l}\text { MFLUCC 12- } \\
0258\end{array}$ & JX399005 & JX399036 & JX399069 \\
\hline Pestalotiopsissp digitalis & MFLU 14-0208 & KP781879 & 781883 & \\
\hline
\end{tabular}


Supplementary Table 1 Continued.

\begin{tabular}{|c|c|c|c|c|}
\hline Taxon & Strain ID & ITS & $t u b$ & tef \\
\hline $\begin{array}{l}\text { Pestalotiopsissp } \\
\text { dracontomelon }\end{array}$ & MFLU 14-0207 & & & KP781880 \\
\hline Pestalotiopsis adusta & ICMP 6088 & JX399006 & JX399037 & JX399070 \\
\hline Pestalotiopsis adusta & $\begin{array}{l}\text { MFLUCC 10- } \\
0146\end{array}$ & JX399007 & JX399038 & JX399071 \\
\hline Pestalotiopsis papuana & CBS 887.96 & KM199318 & KM199415 & KM199492 \\
\hline Pestalotiopsis papuana & CBS 331.96 & KM199321 & KM199413 & KM199491 \\
\hline Pestalotiopsis sp. & CBS 263.33 & KM199316 & KM199414 & KM199489 \\
\hline Pestalotiopsis sp. & CBS 264.33 & KM199322 & KM199412 & KM199490 \\
\hline Pestalotiopsis malayana & CBS 102220 & KM199306 & KM199411 & KM199482 \\
\hline Pestalotiopsis diploclisia & CBS 115585 & KM199315 & KM199417 & KM199483 \\
\hline Pestalotiopsis diploclisia & CBS 115587 & KM199320 & KM199419 & KM199486 \\
\hline Pestalotiopsis diploclisia & CBS 115449 & KM199314 & KM199416 & KM199485 \\
\hline Pestalotiopsis humus & CBS 336.97 & KM199317 & KM199420 & KM199484 \\
\hline Pestalotiopsis humus & CBS 115450 & KM199319 & KM199418 & KM199487 \\
\hline Pestalotiopsis licualacola & HGUP4057 & KC492509 & KC481683 & KC481684 \\
\hline Pestalotiopsis aggestorum & LC8186 & KY464140 & KY464160 & KY464150 \\
\hline Pestalotiopsis aggestorum & LC6301 & KX895015 & KX895348 & KX895234 \\
\hline Pestalotiopsis colombiensis & CBS 118553 & KM199307 & KM199421 & KM199488 \\
\hline Pestalotiopsis jinchanghensis & LC6636 & KX895028 & KX895361 & KX895247 \\
\hline Pestalotiopsis jinchanghensis & LC8 & KY & 64 & KY464154 \\
\hline Pestalotiopsis neolitseae & 17-011 & MH809383 & MH809387 & MH809391 \\
\hline Pestalotiopsis neolitseae & NTUCC 17-012 & MH809384 & MH809388 & MH809392 \\
\hline Pestalotiopsis dilucida & LC3232 & KX894961 & KX895293 & KX895178 \\
\hline Pestalotiopsis dilucida & LC8184 & KY464138 & KY464158 & KY464148 \\
\hline Pestalotiopsis australis & CBS 114193 & KM199332 & KM199383 & KM199475 \\
\hline Pestalotiopsis australis & CBS 111503 & KM199331 & KM199382 & KM199557 \\
\hline Pestalotiopsis yunnanensis & HMAS 96359 & AY373375 & & \\
\hline Pestalotiopsis scoparia & CBS 176.25 & KM199330 & 393 & 99478 \\
\hline Pestalotiopsis jiangxiensis & $\mathrm{LC}$ & 09 & 5341 & KX895227 \\
\hline Pestalotiopsis jinchanghensis & LC4242 & KX895035 & KX895327 & KX895213 \\
\hline Pestalotiopsis unicolor & $\begin{array}{l}\text { MFLUCC 12- } \\
0275\end{array}$ & JX398998 & JX399029 & JX399063 \\
\hline Pestalotiopsis unicolor & $\begin{array}{l}\text { MFLUCC 12- } \\
0276\end{array}$ & JX398999 & JX399030 & - \\
\hline Pestalotiopsis intermedia & $\begin{array}{l}\text { MFLUCC 12- } \\
0259\end{array}$ & JX398993 & JX399028 & JX399059 \\
\hline Pestalotiopsis linearis & $\begin{array}{l}\text { MFLUCC 12- } \\
0271\end{array}$ & JX398992 & JX399027 & JX399058 \\
\hline Pestalotiopsis chamaeropis & CBS 186.71 & KM199326 & KM199391 & KM199473 \\
\hline Pestalotiopsis chamaeropis & CBS 113607 & KM199325 & KM199390 & KM199472 \\
\hline Pestalotiopsis hollandica & CBS 265.33 & KM199328 & KM199388 & KM199481 \\
\hline Pestalotiopsis brassicae & CBS 170.26 & KM199379 & & KM199558 \\
\hline
\end{tabular}


Supplementary Table 1 Continued.

\begin{tabular}{|c|c|c|c|c|}
\hline Taxon & Strain ID & ITS & $t u b$ & tef \\
\hline Pestalotiopsis verruculosa & $\begin{array}{l}\text { MFLUCC 12- } \\
0274\end{array}$ & JX398996 & & JX399061 \\
\hline Pestalotiopsis sequoiae & $\begin{array}{l}\text { MFLUCC 13- } \\
0399\end{array}$ & KX572339 & & \\
\hline Pestalotiopsis monochaeta & CBS 144.97 & KM199327 & KM199386 & KM199479 \\
\hline Pestalotiopsis monochaeta & CBS 440.83 & KM199329 & KM199387 & KM199480 \\
\hline Pestalotiopsis italiana & $\begin{array}{l}\text { MFLUCC 12- } \\
0657\end{array}$ & KP781878 & KP781882 & KP781881 \\
\hline Pestalotiopsis lushanensis & LC4344 & KX895005 & KX895337 & KX895223 \\
\hline Pestalotiopsis lushanensis & LC8182 & KY464136 & KY464156 & KY464146 \\
\hline Pestalotiopsis rhododendri & IFRDCC 2399 & KC537804 & KC537818 & KC537811 \\
\hline Pestalotiopsis clavata & $\begin{array}{l}\text { MFLUCC 12- } \\
0268\end{array}$ & JX398990 & JX399025 & JX399056 \\
\hline Pestalotiopsis inflexa & $\begin{array}{l}\text { MFLUCC 12- } \\
0270\end{array}$ & JX399008 & JX399039 & JX399072 \\
\hline Pestalotiopsis portugalica & CBS 393.48 & KM199335 & KM199422 & KM199510 \\
\hline Pestalotiopsis portugalica & LC2929 & KX894921 & KX895253 & KX895138 \\
\hline Pestalotiopsis yanglingensis & LC4553 & KX895012 & KX895345 & KX895231 \\
\hline Pestalotiopsis yanglingensis & LC3067 & KX894949 & KX895281 & KX895166 \\
\hline Pestalotiopsis camelliae & $\begin{array}{l}\text { MFLUCC 12- } \\
0277\end{array}$ & JX399010 & JX399041 & JX399074 \\
\hline Pestalotiopsis camelliae & CBS 443.62 & KM199336 & KM199424 & KM199512 \\
\hline Pestalotiopsis furcata & $\begin{array}{l}\text { MFLUCC 12- } \\
0054\end{array}$ & JQ683724 & JQ683708 & JQ683740 \\
\hline Pestalotiopsis furcata & LC6303 & KX895016 & KX895349 & KX895235 \\
\hline Pestalotiopsis sp. & LC6576 & KX895021 & KX895354 & KX895240 \\
\hline $\begin{array}{l}\text { Pestalotiopsis } \\
\text { longiappendiculata }\end{array}$ & LC3013 & KX894939 & KX895271 & KX895156 \\
\hline $\begin{array}{l}\text { Pestalotiopsis } \\
\text { novaehollandiae }\end{array}$ & CBS 130973 & KM199337 & KM199425 & KM199511 \\
\hline Pestalotiopsis gaultheria & OP137 & KC537805 & KC537819 & KC537812 \\
\hline Pestalotiopsis spathulata & CBS 356.86 & KM199338 & KM199423 & KM199513 \\
\hline Pestalotiopsis diversiseta & $\begin{array}{l}\text { MFLUCC 12- } \\
0287\end{array}$ & JX399009 & JX399040 & JX399073 \\
\hline Pestalotiopsis arengae & CBS 331.92 & KM199340 & KM199426 & KM199515 \\
\hline Pestalotiopsis hawaiiensis & CBS 114491 & KM199339 & KM199428 & KM199514 \\
\hline Pestalotiopsis arceuthobii & CBS 434.65 & KM199341 & KM199427 & KM199516 \\
\hline $\begin{array}{l}\text { Pestalotiopsis } \\
\text { anacardiacearum }\end{array}$ & IFRDCC 2397 & KC247154 & KC247155 & KC247156 \\
\hline Pestalotiopsis jesteri & CBS 109350 & KM199380 & KM199468 & KM199554 \\
\hline Neopestalotiopsis saprophyta & $\begin{array}{l}\text { MFLUCC-12- } \\
0282\end{array}$ & JX398982 & JX399017 & JX399048 \\
\hline
\end{tabular}


Supplementary Table 2 A summary of characters of species of Pestalotiopsis

\begin{tabular}{|c|c|c|c|c|c|c|c|c|c|}
\hline $\begin{array}{l}\text { Pestalotiopsis } \\
\text { Species }\end{array}$ & $\begin{array}{l}\text { Conidiogenous } \\
\text { cells }(\mu \mathrm{m})\end{array}$ & $\begin{array}{l}\text { Conidia size } \\
(\mu \mathrm{m})\end{array}$ & \begin{tabular}{|l|} 
No. of apical \\
appendages
\end{tabular} & $\begin{array}{l}\text { Branched or } \\
\text { unbranched }\end{array}$ & $\begin{array}{l}\text { Length of } \\
\text { apicalappendages } \\
(\mu \mathrm{m})\end{array}$ & $\begin{array}{l}\text { No. of basal } \\
\text { appendages }\end{array}$ & $\begin{array}{l}\text { Branched or } \\
\text { unbranched }\end{array}$ & $\begin{array}{l}\text { Length of basal } \\
\text { appendages } \\
(\mu \mathrm{m})\end{array}$ & Reference \\
\hline P. formosana & $\begin{array}{l}(5-) 9-15(-19) \times \\
(2-) 2-3(-4)\end{array}$ & $\begin{array}{l}(15-) 18-22(- \\
26) \times(5-) 6- \\
7(-7)\end{array}$ & $\begin{array}{l}2-3 \text { (mostly } \\
2)\end{array}$ & unbranched & $(8-) 11-16(-20)$ & 1 & unbranched & $(2-) 3-5(-6)$ & This study \\
\hline P. neolitseae & $\begin{array}{l}(6-) 7-11(-13) \times \\
(2-) 2-4(-5)\end{array}$ & $\begin{array}{l}(15-) 18-21(- \\
25) \times(4-) 5- \\
6(-6) \\
\end{array}$ & $\begin{array}{l}\text { 1-3 (mostly } \\
\text { 2) }\end{array}$ & unbranched & $(7-) 10-15(-17)$ & 1 & unbranched & $2-5$ & This study \\
\hline $\begin{array}{l}P . \\
\text { jinchanghensis }\end{array}$ & $5-12 \times 2-7$ & $\begin{array}{l}22-32 \times 5.5- \\
8.5\end{array}$ & $\begin{array}{l}\text { 1-3 (mostly } \\
2)\end{array}$ & unbranched & $15-33.5$ & $1-2$ & unbranched & $5.5-15.5$ & $\begin{array}{l}\text { Liu et al. } \\
2017\end{array}$ \\
\hline P. parva & $5-18 \times 2-4$ & $\begin{array}{l}(16-) 16.5- \\
20(-21) \times 5- \\
7(-7.5)\end{array}$ & $\begin{array}{l}2-3 \text { (mostly } \\
3 \text { ) }\end{array}$ & unbranched & $(6-) 6.5-12(-13)$ & 1 & unbranched & $2-4$ & $\begin{array}{l}\text { Liu et al. } \\
2017\end{array}$ \\
\hline P. maculans & $5-15 \times 2-4$ & $\begin{array}{l}19-27.5 \times 6- \\
8.5\end{array}$ & $2-3$ & unbranched & $3-4$ & 1 & unbranched & $1.5-3$ & $\begin{array}{l}\text { Nag Raj } \\
1985\end{array}$ \\
\hline
\end{tabular}

